Jurnal Indonesia Sosial Teknologi:p-ISSN: 2723 - 6609

e-ISSN :2745-5254

Vol. 3, No.1 Januari 2022

\title{
PROTOTIPE SISTEM MONITORING KEBOCORAN PIPA DISTRIBUSI AIR BERBASIS SCADA
}

\author{
Tubagus Sundana ${ }^{1}$, Farchan Aditya Johari' ${ }^{2}$, Fathan Al Ariiq ${ }^{3}$. \\ Jurusan Teknik Elektro, Politeknik Negeri Bandung, Indonesia \\ Email : tubagus.sundana.tele418@polban.ac.id ${ }^{1}$, farhanadityajohari12345@gmail.com², \\ fathan.al.tele419@polban.ac.id ${ }^{3}$
}

\begin{abstract}
Abstrak
Kebocoran pipa jaringan distribusi air masih sering terjadi dan dapat mengakibatkan kerugian yang cukup besar bagi semua pihak yang terlibat, baik itu penyalur maupun konsumen. Maka dari itu, penanganan terhadap kebocoran pipa ini perlu cepat dilakukan. Metode yang digunakan sekarang umumnya masih bersifat manual, yaitu dengan mengecek langsung ke lokasi serta berdasarkan laporan masyarakat. Penelitian ini bertujuan untuk membuat suatu sistem yang dapat memantau kondisi debit air serta melokalisir letak kebocoran dari suatu pipa jaringan distribusi air dengan memantaunya pada suatu HMI (Human Machine Interface) SCADA, sehingga kebocoran dapat dideteksi lebih dini. Prinsip pendeteksian kebocoran didasarkan pada teori kontinuitas, debit air saluran masuk harus sama dengan saluran keluar. Dua buah sensor flow meter digunakan untuk mengukur debit air pada dua titik, jika terdapat perbedaan debit air yang signifikan, maka dapat dipastikan ada kebocoran di antara dua titik tersebut. Hasil penelitian menunjukkan bahwa sistem berhasil melokalisir letak kebocoran dan memberi peringatan berupa alarm pada HMI. Alarm memiliki 3 level, yaitu Normal, Warning, dan Danger direpresentasikan dengan indikator warna hijau, kuning dan merah. Pendeteksian kebocoran berhasil dilakukan pada setiap lokasi dengan menghitung nilai deviasi antara dua titik pengukuran. Pada penelitian ini didapat untuk kondisi Warning, deviasi $>7 \%$ dan $<=10 \%$, sedangkan untuk kondisi Danger, deviasi $>10 \%$, dimana terdeteksi adanya perbedaan debit air sebesar $18.18 \%$ antara flow 1 dan 2 serta perbedaan debit air sebesar $22.22 \%$ antara flow 2 dan flow 3 , sehingga alarm pun berwarna merah.
\end{abstract}

Kata kunci: Kebocoran Pipa; Teori Kontinuitas; HMI SCADA; deviasi; flow meter

\begin{abstract}
:
Water distribution network pipe leaks are still common and can result in considerable losses for all parties involved, both distributors and consumers. Therefore, the handling of this pipe leak needs to be done quickly. The method used today is generally still manual, namely by checking directly at the location and based on community reports. This study aims to create a system that can monitor the condition of water discharge and localize the location of the leak from a water distribution network pipe by monitoring it on a SCADA (Human Machine Interface) HMI, so that leaks can be detected early. The principle of leak detection is based on the continuity theory, where the inlet water discharge must be the same as the
\end{abstract}


outlet. By using two flow meter sensors, the water discharge at two points will be measured and if there is a significant difference in water flow, it can be ascertained that there is a leak between the two points. The results showed that the system was successful in locating the location of the leak and giving a warning in the form of an alarm to the HMI. The alarm has 3 levels, namely Normal, Warning, and Danger represented by green, yellow and red color indicators. Leak detection was successfully carried out at each location by calculating the deviation value between the two measurement points. In this study, the deviation was $>7 \%$ and $<=10 \%$ for Warning conditions, while for Danger conditions, deviation was $>10 \%$.

Keyword: Pipe Leakage; Continuity Theory; HMI SCADA; deviation; flow meter

\section{Pendahuluan}

Air merupakan sumber daya alam yang menjadi salah satu kebutuhan utama bagi manusia. Sumber daya alam ini perlu diolah dan didistribusikan untuk mendapatkan kuantitas dan kualitas yang cukup untuk dikonsumsi (Kusumawardani, 2011). Pendistribusian air dilakukan dengan mendistribusikan air dari instalasi pengolahan menuju pemukiman, perindustrian, dan perkantoran (Tetty, S. R., Maman, A. and Novian, 2015). Oleh karena itu maka perlu dipastikan bahwa pendistribusian air tidak mengalami kendala seperti kehilangan air atau kebocoran (Pratama Putra, 2014).

Kebocoran pipa jaringan distribusi air dapat menyebabkan berbagai kerugian yang berdampak besar bagi pihak-pihak yang terkait dalam sistem perpipaan (Wijaya \& Pulungan, 2017). Sebagai contoh, di Tirtawening Kota Bandung pada April, 2017 terjadi kebocoran pipa jaringan air terdistribusi. Dengan adanya kebocoran tersebut, yang mana semula pipa menghantarkan air sebesar \pm 650 1/detik berkurang menjadi \pm 375 1/detik. Akibat pecahnya pipa tersebut, sekitar 102,820 Sambungan Langganan (SL) terganggu selama 5 hari (PDAM Tirtawening Kota Bandung, 2017).

Penangananan terhadap kebocoran pipa jaringan distribusi perlu dilakukan dengan dengan cepat agar meminimalisir dampak dari kebocoran pipa jaringan distribusi (Heston \& Pasawati, 2016). Metode yang digunakan untuk mendeteksi kebocoran pipa jaringan distribusi umumnya masih dilakukan secara manual yaitu dengan mengecek langsung ke daerah distribusi atau berdasarkan laporan masyarakat tentang adanya kebocoran air pada jaringan pipa distribusi. Pendeteksian dengan cara ini kurang efektif karena membutuhkan waktu yang cukup lama untuk mendeteksi adanya kebocoran pipa jaringan distribusi (Hariyanto, Pauzi, \& Supriyanto, 2017).

Merujuk pada persamaan kontinuitas, untuk aliran yang mengalir pada pipa dengan volume tetap, selama aliran debit air tetap dan tidak terjadi penambahan cairan, maka laju aliran pada saluran masuk dan saluran keluar pipa harus bernilai sama (Herwindo \& Rahmandani, 2018). (Munson B., 2004) Jika terjadi suatu kebocoran dalam sistem distribusi fluida, maka akan terjadi perbedaan antara debit fluida masuk dan debit fluida keluar.

Berdasarkan paparan di atas, dengan menggunakan dua buah sensor flowmeter yang ditempatkan pada dua titik pipa, dengan tujuan untuk merekam data perbedaan 
debit air di kedua titik tersebut, maka dapat dilakukan pemantauan terhadap jaringan pipa distribusi tersebut guna mempersingkat waktu dan dapat mendeteksi secara dini letak kebocoran saluran pipa tersebut (Briantama, Akbar, \& Aziz, 2021). Maka langkah korektif bisa segera dilakukan dan konsumen tidak akan terganggu terlalu lama (Sadeghioon, Metje, Chapman, \& Anthony, 2014). Maka dari itu, "Sistem Monitoring Kebocoran Pipa Distribusi Air berbasis SCADA" ini dibuat untuk memonitoring dan mendeteksi lebih dini kebocoran yang terjadi pada saluran pipa. Perbedaan utama penelitian ini dengan penelitian lain adalah digunakannya sistem SCADA, dengan jaringan RS485, yang mana dapat menjangkau komunikasi beberapa km. Dengan adanya penelitian ini maka diharapkan jaringan pipa distribusi air dapat secara realtime terpantau dengan basis SCADA, sehingga memudahkan perawatan dan perbaikan pipa.

\section{Metode Penelitian}

\section{A. Prinsip Kerja Sistem}

Deteksi kebocoran pipa pada sistem yang akan dibuat ini, hanya untuk kasus pipa saluran utama, artinya belum melewati cabang lain dan pipa pun ditempatkan pada ketinggian yang sama. Cara kerja dari sistem ini adalah dengan mengukur debit air di setiap titik pengukuran, selanjutnya akan dilakukan perbandingan jumlah debit air diantara dua titik. Sesuai dengan persamaan kontinuitas, bahwa laju aliran fluida yang masuk ke dalam volume tersebut harus sama dengan laju aliran yang keluar dari volume, maka jika ternyata ditemukan debit air tidak sama diantara dua titik, maka dapat dipastikan kebocoran ada di antara kedua titik tersebut, dengan begitu kita dapat melokalisir titik kebocoran. Pada penelitian ini, diibaratkan ada 3 titik pengukuran, seperti ditunjukkan gambar berikut

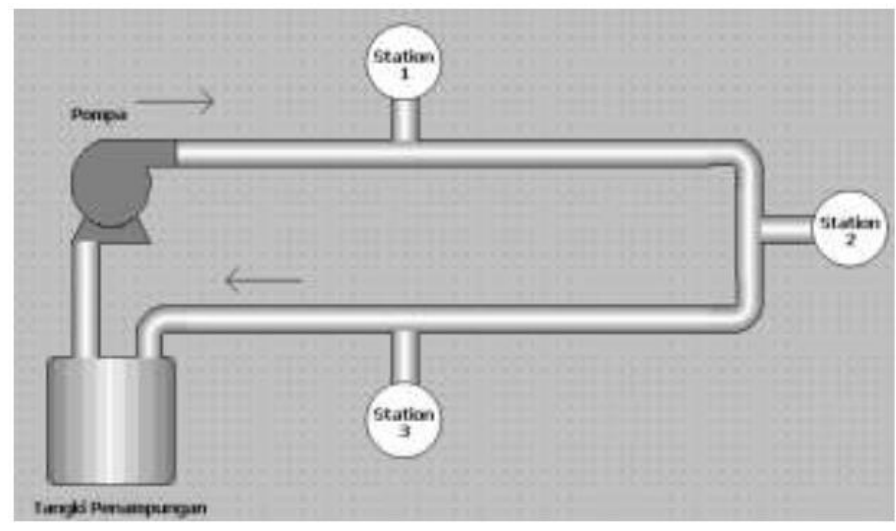

Gambar-1 Konsep Sistem Deteksi Kebocoran pada Saluran Air

Pada setiap station dipasang sensor debit air dan pada sistem ini hanya disimulasikan 3 stasiun pengukuran artinya hanya ada dua daerah perkiraan titik kebocoran, namun pada realnya tentunya stasiun tersebut dapat diperbanyak. 


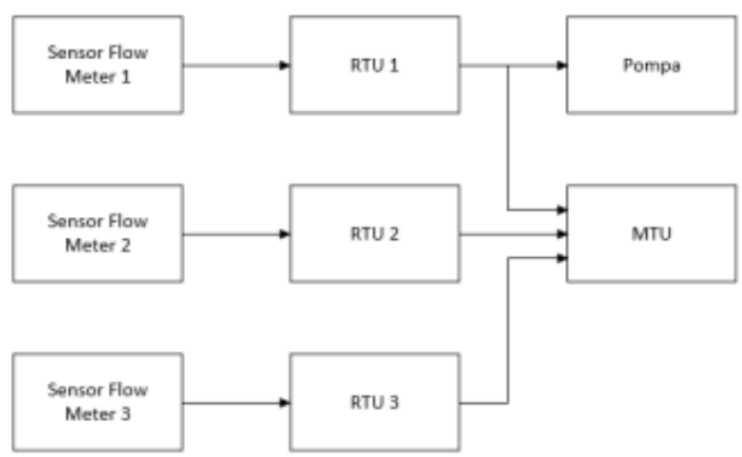

Gambar-2 Diagram Blok Sistem

Gambar-2 menunjukkan diagram blok sistem. Sistem ini dibangun oleh 3 RTU, yang mana masing-masing RTU tersebut disimpan pada masing-masing station pengukuran debit air. Khusus RTU1, sekaligus dapat mengontrol pompa untuk mengalirkan air. RTU dan MTU berkomunikasi melalui protocol Modbus yang mana pada MTU komunikasi tersebut di handle oleh OPC, dalam hal ini menggunakan aplikasi KepServer. Data pada KepServer tersebut akan ditampilkan melalui HMI SCADA, begitupun dengan perintah controlnya.

\section{B. Desain Perangkat Lunak}

Pada bagian ini dibuat rancangan layout untuk window pada HMI. Berikut rancangan layout HMI:

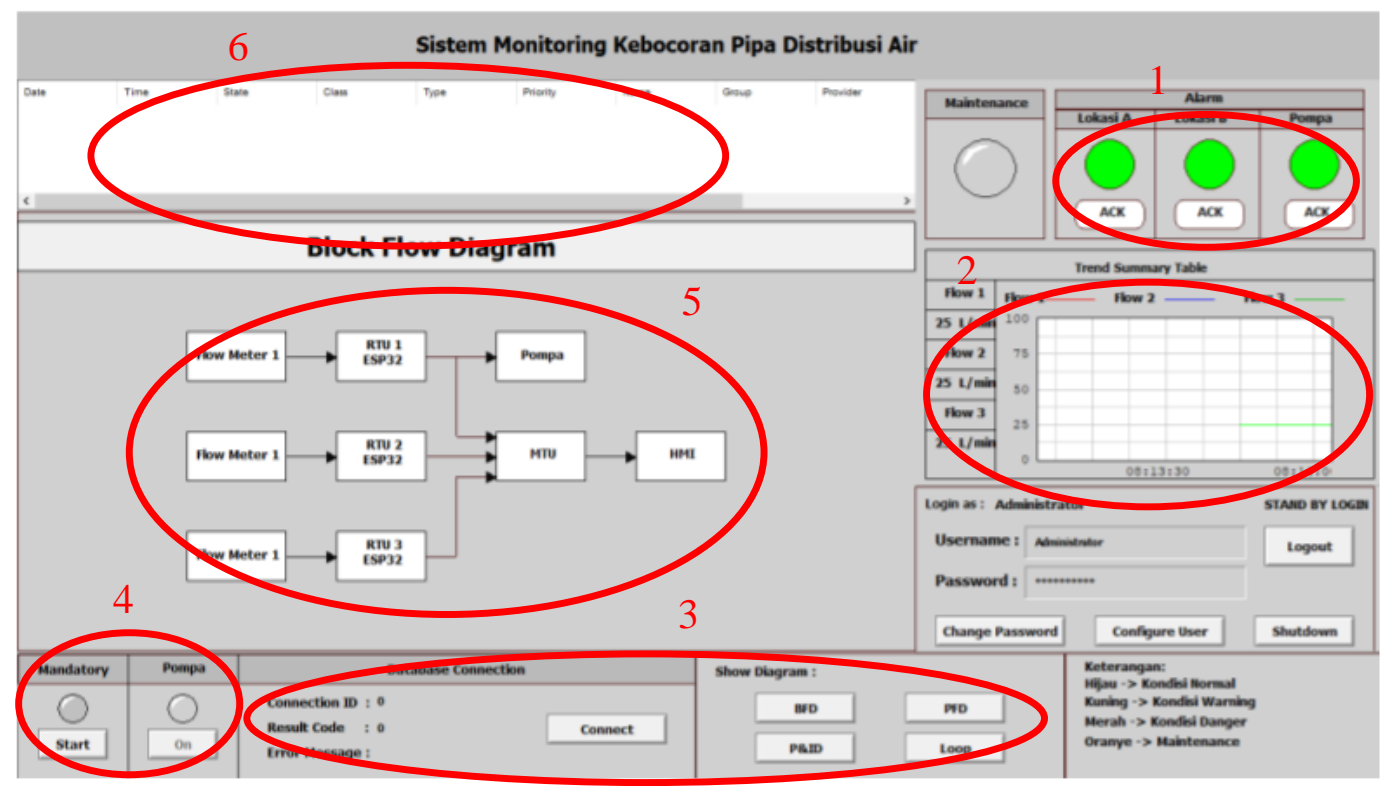

Gambar-3 Rancangan HMI Utama

1. Alarm dan maintenanace indikator

Bagian ini akan menunjukkan indikator alarm dan juga maintenance yaitu berupa lampu. Pada bagian ini berfungsi agar saat terjadi alarm tersebut, perhatian operator dapat langsung tertuju ke bagian ini.

2. Data summary 
Bagian ini akan menunjukkan data hasil pengukuran dari RTU dalam bentuk grafik. Hal ini berguna agar trend dari denit ait dapat cepat dipahami.

3. Tombol navigasi diagram dan koneksi database

Bagian ini akan menunjukkan tombol navigasi untuk berpindah-pindah ke halaman diagram yang diinginkan serta untuk mengkoneksikan database.

4. Panel kontrol

Bagian ini untuk menempatkan tombol-tombol kontrol seperti mandatory dan control pompa.

5. Display

Bagian ini untuk menampilkan diagram yang dipilih pada panel kontrol.

6. Tabel ack alarm

Bagian ini menunjukkan daftar alarm jika ada alarm yang tertigger, dalam hal ini berarti jika ada kebocoran.

C. Desain Mekanik

Perancangan mekanik dalam alat ini sangatlah penting, karena untuk mensimulasikan aliran air. Maka dari itu, pada sistem ini, digunakan pipa PVC $1 \frac{1}{2}$ inchi sebagai media pendistribusian air. Berikut ini adalah gambaran mekanik dari alat ini.

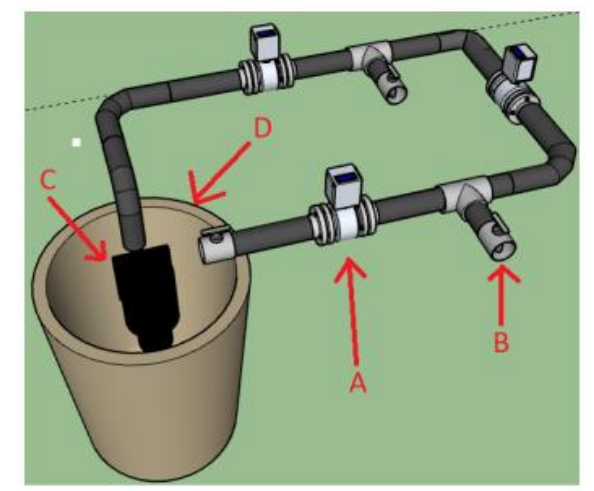

Gambar-4 Bagian-bagian Mekanik Simulasi Kebocoran Pipa

Ada beberapa bagian penting dalam desain mekanik ini,yakni:

A : Flow meter, dipasang pada 3 titik. Kebocoran akan dideteksi di lokasi antara titik 1 dan 2 serta lokasi antara titik 2 dan 3

B : Keran simulasi kebocoran. Keran ini digunakan untuk mensimulasikan adanya kebocoran, dipasang di dua lokasi. Tempat persisnya diletakkan diantara dua sensor flow meter.

$\mathrm{C}$ : Pompa air untuk mengalirkan air ke pipa distribusi.

D : Ember penampung air, untuk sumber penampung air dalam simulasi sistem ini.

D. Komponen Pendukung Sistem 
Sistem ini terdiri dari beberapa RTU, yang mana di dalam RTU tersebut terdapat sebuah mikrokontroler dan sensor. Berikut ini penjelasan secara khusus mengenai komponen pendukung yang digunakan dalam sistem ini:

\section{ESP32}

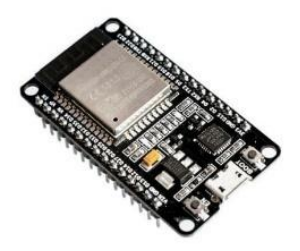

Gambar-5 ESP32

ESP32 pada masing-masing RTU befungsi sebagai mikrokontroler dan pengolah atau pemroses data dari sensor flow meter serta pemroses command dari MTU. Khusus untuk ESP32 pada RTU1 berfungsi juga untuk mengendalikan relay.

2. Flow Meter YF-S201

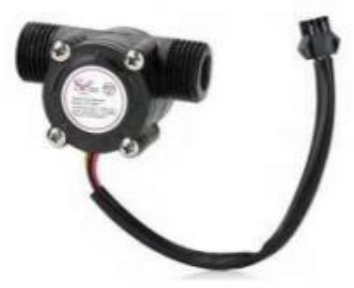

Gambar-6 Flow Meter

Flow meter YF-S201 berfungsi untuk mengambil data analog dari pengukuran debit air dengan menggunakan prinsip efek hal.

3. UART TTL to RS485

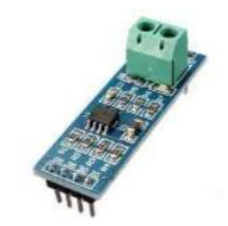

Gambar-7 UART to RS485

UART TTL to RS485 berfungsi untuk mengonversi antarmuka UART yang ada pada ESP32 menjadi serial RS485 sehingga dapat berkomunikasi dengan MTU melalui jaringan RS485.

\section{Hasil dan Pembahasan}

A. Realisasi Perangkat Lunak

Perangkat lunak sistem terbagi yaitu tampilah HMI dan juga koneksi ke database serta mekanisme login ke aplikasi. Berikut merupakan realisasi perangkat lunak sistem: 
Tubagus Sundana, Farchan Aditya Johari dan Fathan Al Ariiq

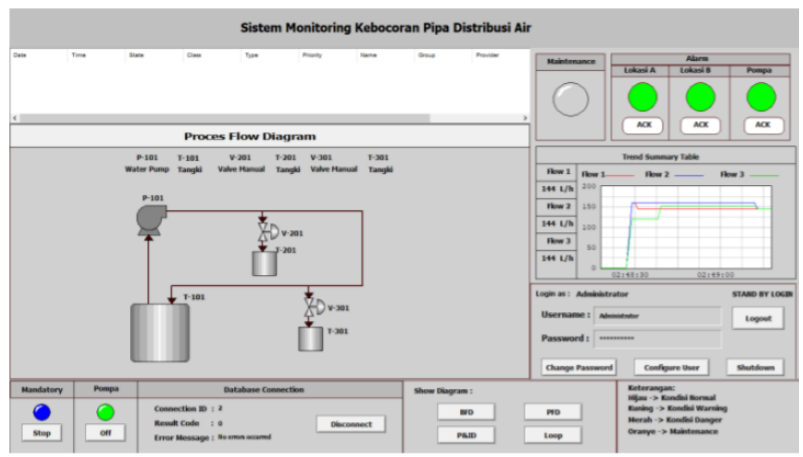

Gambar-8 Tampilan hasil realisasi HMI

\begin{tabular}{|c|c|c|c|c|c|c|c|}
\hline \\
\hline Current_Dat & Current_Tin - & Flow1 & Flow2 & Flow3 & - Deviasia & - DeviasiB & Click to Add \\
\hline & & 0 & 0 & 0 & 0 & 0 & \\
\hline $08 / 08 / 2021$ & $02: 46: 15$ & 0 & 0 & 0 & 0 & 0 & \\
\hline $08 / 08 / 2021$ & $02: 46: 20$ & 0 & 0 & 0 & 0 & 0 & \\
\hline $08 / 08 / 2021$ & $02: 46: 25$ & 0 & 0 & 0 & 0 & 0 & \\
\hline 08/08/2021 & 02:46:30 & 0 & 0 & 0 & 0 & 0 & \\
\hline $08 / 08 / 2021$ & $02: 46: 35$ & 0 & 0 & 0 & 0 & 0 & \\
\hline $08 / 08 / 2021$ & $02: 46: 40$ & 0 & 0 & 0 & 0 & 0 & \\
\hline $08 / 08 / 2021$ & $02: 46: 45$ & 0 & 0 & 0 & 0 & 0 & \\
\hline 08/08/2021 & $02: 46: 50$ & 0 & 0 & 0 & 0 & 0 & \\
\hline 08/08/2021 & $02: 46: 55$ & 0 & 0 & 0 & 0 & 0 & \\
\hline 08/08/2021 & $02: 47: 00$ & 0 & 0 & 0 & 0 & 0 & \\
\hline $08 / 08 / 2021$ & 02:47:05 & 0 & 0 & 0 & 0 & 0 & \\
\hline 08/08/2021 & $02: 48: 25$ & 144 & 160 & 120 & -11 & 25 & \\
\hline $08 / 08 / 2021$ & $02: 48: 30$ & 144 & 160 & 120 & -11 & 25 & \\
\hline $08 / 08 / 2021$ & $02: 48: 35$ & 144 & 160 & 152 & -11 & 5 & \\
\hline $08 / 08 / 2021$ & $02: 48: 40$ & 144 & 160 & 152 & -11 & 5 & \\
\hline 08/08/2021 & $02: 48: 45$ & 144 & 160 & 152 & -11 & 5 & \\
\hline 08/08/2021 & $02: 48: 50$ & 144 & 160 & 152 & -11 & 5 & \\
\hline $08 / 08 / 2021$ & $02: 48: 55$ & 144 & 160 & 152 & -11 & 5 & \\
\hline 08/08/2021 & $02: 49: 00$ & 144 & 160 & 152 & -11 & 5 & \\
\hline $08 / 08 / 2021$ & $02: 49: 05$ & 144 & 160 & 152 & -11 & 5 & \\
\hline $08 / 08 / 2021$ & $02: 49: 10$ & 144 & 144 & 144 & 0 & 0 & \\
\hline 08/08/2021 & $02: 49: 15$ & 144 & 144 & 144 & 0 & 0 & \\
\hline 08/08/2021 & $02: 49: 20$ & 144 & 144 & 144 & 0 & 0 & \\
\hline
\end{tabular}

Gambar-9 Hasil rekaman database

Data sudah berhasil terkoneksi dengan database pada Microsoft Acces, dan direkam setiap 5 detik sekali jika tombol connect pada HMI sudah diaktifkan.

B. Realisasi Perangkat Keras

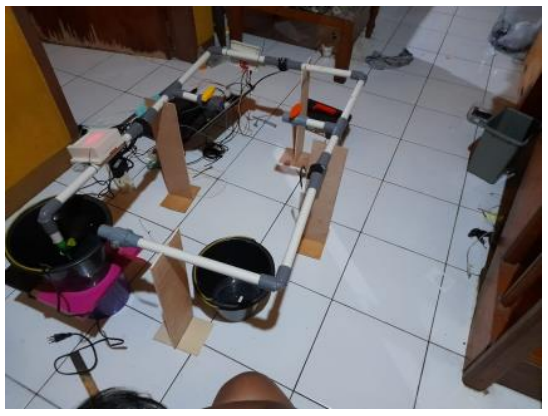

Gambar-10 Realisasi plant secara keseluruhan

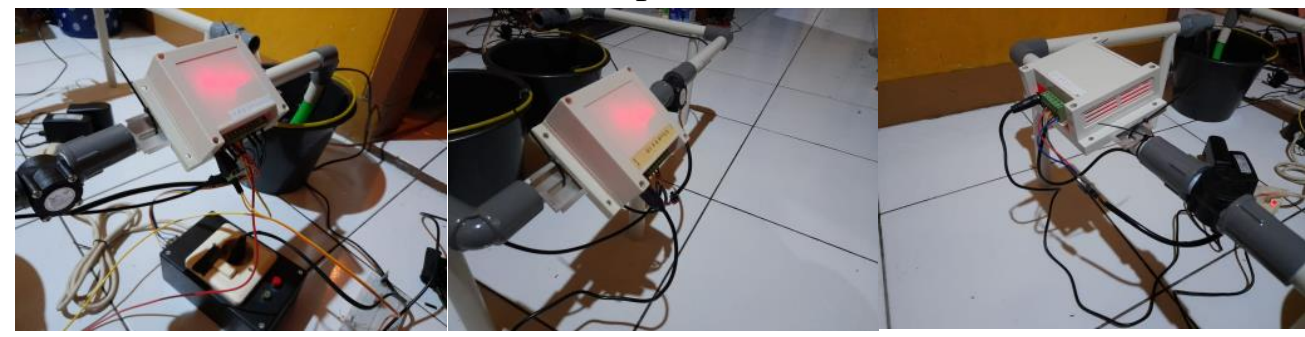

Gambar-11 Realisasi RTU1,RTU2 dan RTU3 
C. Pengujian Sistem

Pengujian sistem dilakukan dalam skala laboratorium, dimana sistem yang diuji masih berupa prototiper. Berikut ini merupakan hasil pengujian daari sistem.

1. Simulasi Alarm Kebocoran

Kebocoran pipa dideteksi dengan cara menghitung deviasi nilai hasil pengukuran flow meter pada titik tertentu, jika didapat perbedaan yang signifikan antara dua titik pengukuran flow tersebut, maka dapat diduga terjadi kebocoran pada titik tersebut. Titik acuan deviasi mengacu pada titik pengukuran sebelumnya. Perhitungan deviasi tidak dimunculkan dalam tampilan HMI, karena sebagai proses latar belakang untuk alarm saja. Deviasi dihitung dengan cara berikut.

Deviasi titik $\mathrm{A}=\frac{\text { Flow } 1-\text { Flow } 2}{\text { Flow } 1} \times 100 \%$

Deviasi titik B $=\frac{\text { Flow 2-Flow } 3}{\text { Flow } 2} \times 100 \%$

Ada 3 indikator level alarm, yakni sebagai berikut.

- Normal, indikator berwarna hijau dan deviasi antara flow meter $<=7 \%$.

- Warning, indikator berwarna kuning dan deviasi antara flow meter $>7 \%$ dan $<=10 \%$.

- Danger, indikator berwarna merah dan deviasi antara flow meter $>10 \%$.

Dilakukan beberapa percobaan kebococran pada beberapa titik, berikut ini merupakan hasilnya.

a. Keadaan Normal

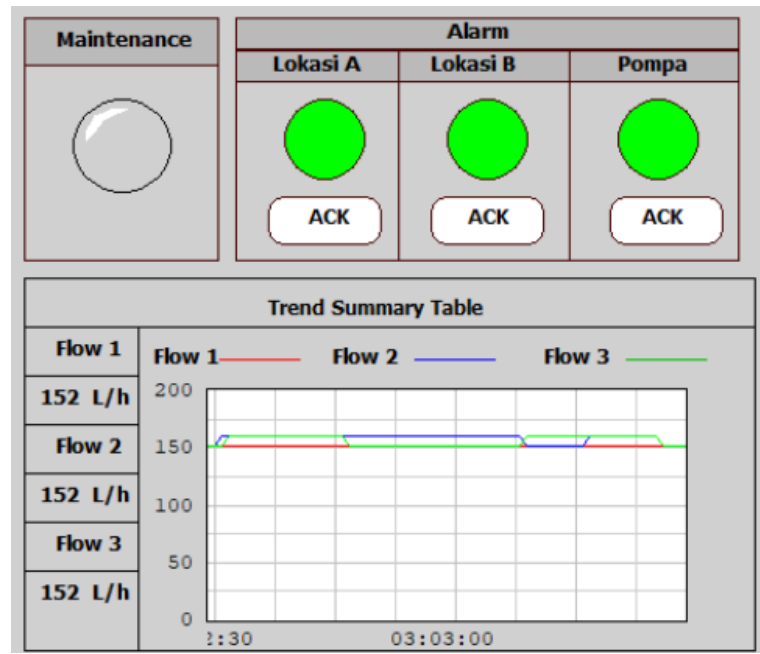

Gambar-12 Tampilan alarm dan trend saat keadaan tidak ada kebocoran

Pada gambar diatas, pembacaan sensor flow meter kadang berubah2, hal ini dikarenakan resolusi dari flow meter itu sendiri sebesar $8 \mathrm{~L} /$ jam, sehingga ada perbedaan sedikit saja terdeteksinya berbeda $8 \mathrm{~L} / \mathrm{jam}$.

b. Kebocoran titik A (Antara RTU 1 dan RTU 2)

- Level Alarm Warning (Deviasi Flow >7\%) 


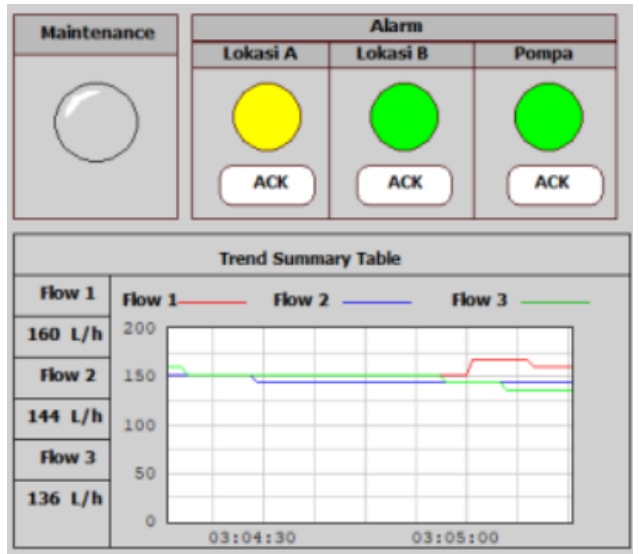

Gambar-13 Tampilan alarm dan trend saat deviasi flow $>7 \%$ dan $<=10 \%$

Deviasi titik $\mathrm{A}=\frac{160-144}{160} \times 100 \%=10 \%$

Oleh karena deviasinya masih $10 \%$, maka indicator alarmnya pun masih berwarna kuning.

- Level Alarm Danger (Deviasi Flow >10\%)

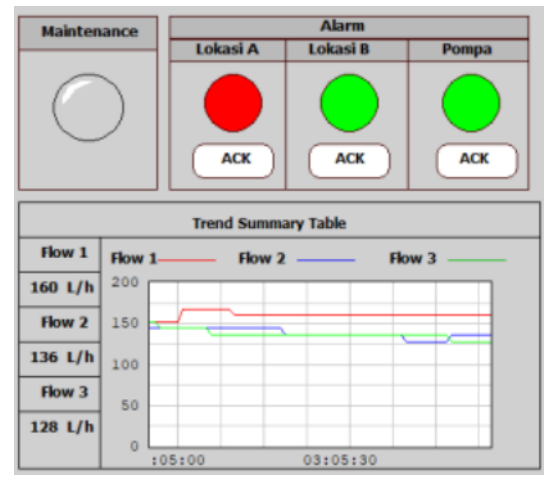

Gambar-14 Tampilan Alarm dan Trend saat deviasi flow $>10 \%$

Deviasi titik $A=\frac{160-136}{160} \times 100 \%=15 \%$

Pada gambar 14, terdeteksi adanya perbedaan debit air sebesar $15 \%$ antara flow 1 dan 2 sehingga alarm untuk lokasi A pun berwarna merah.

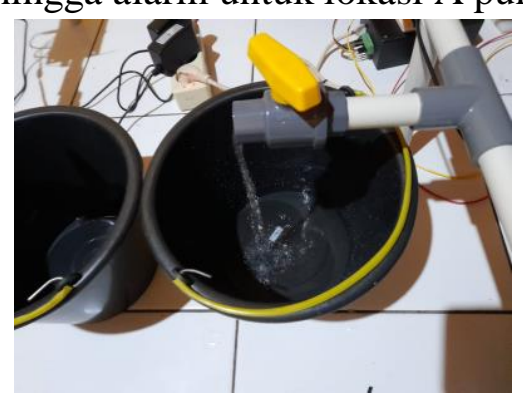

Gambar-15 Proses simulasi kebocoran plant pada titik A

c. Kebocoran titik B (Antara RTU 2 dan RTU 3)

- Level Alarm Warning (Deviasi Flow >7\%) 


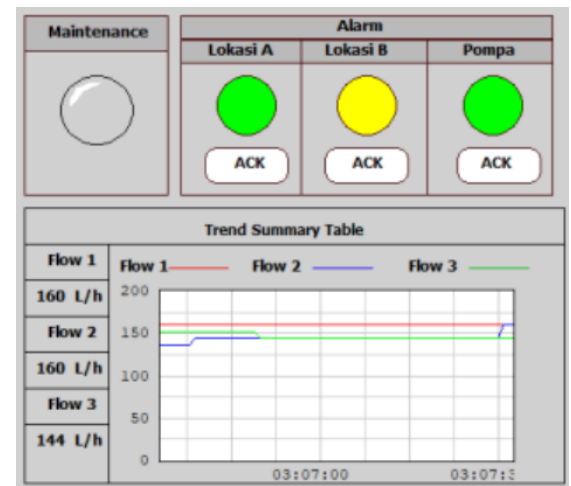

Gambar-16 Tampilan Alarm dan Trend saat deviasi flow $>=7 \%$

Deviasi titik B $=\frac{160-144}{160} \times 100 \%=10 \%$

Pada gambar 16, terdeteksi adanya perbedaan debit air sebesar $10 \%$ antara flow 2 dan 3 sehingga alarm untuk lokasi B pun berwarna kuning.

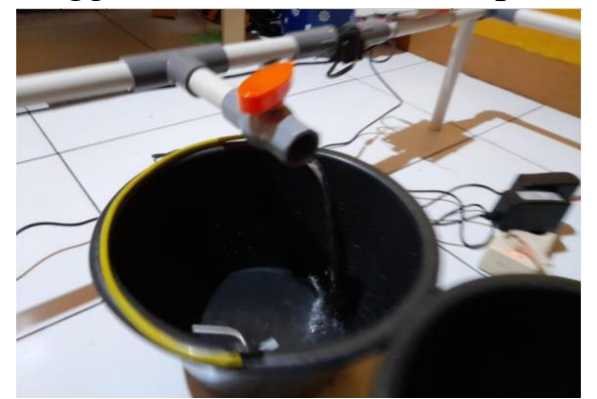

Gambar-17 Proses simulasi kebocoran pada titik B saat deviasi flow $>7 \%$

- $\quad$ Level Alarm Danger (Deviasi Flow >10\%)

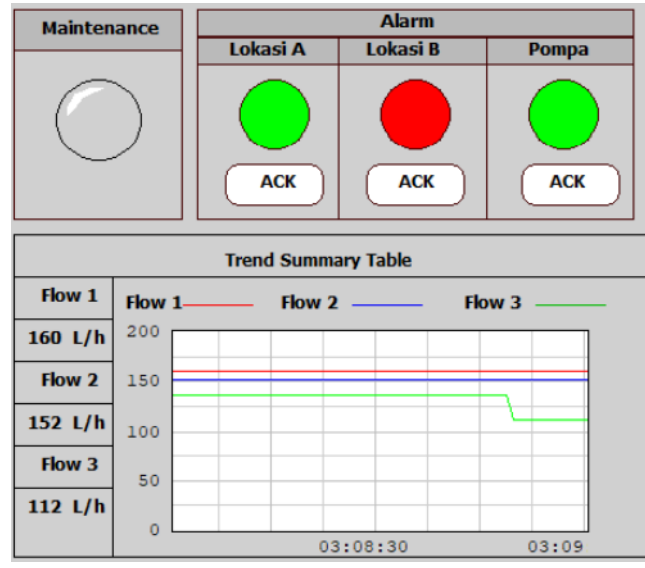

Gambar-18 Tampilan Alarm dan Trend saat deviasi flow > 10\%

Deviasi titik B $=\frac{152-112}{152} \times 100 \%=26.31 \%$

Pada gambar 18, terdeteksi adanya perbedaan debit air sebesar $26.31 \%$ antara flow 2 dan 3 sehingga alarm untuk lokasi B pun berwarna merah. 


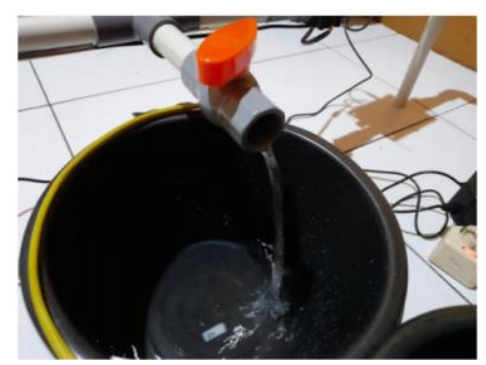

Gambar-19 Proses simulasi kebocoran pada titik B saat deviasi flow $>10 \%$

d. Kebocoran dua titik (Lokasi A dan B)

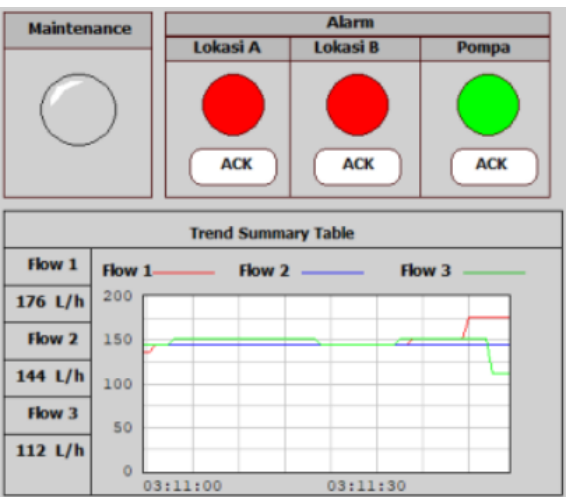

Gambar-20 Tampilan alarm dan trend saat simulasi kebocoran pada kedua titik

Deviasi titik $\mathrm{A}=\frac{176-144}{176} \times 100 \%=18.18 \%$

Deviasi titik B $=\frac{144-112}{144} \times 100 \%=22.22 \%$

Pada gambar 20, terdeteksi adanya perbedaan debit air sebesaar $18.18 \%$ antara flow 1 dan 2 serta perbedaan debit air sebesar 22.22\% antara flow 2 dan flow 3, sehingga alarm untuk lokasi A dan B pun berwarna merah.

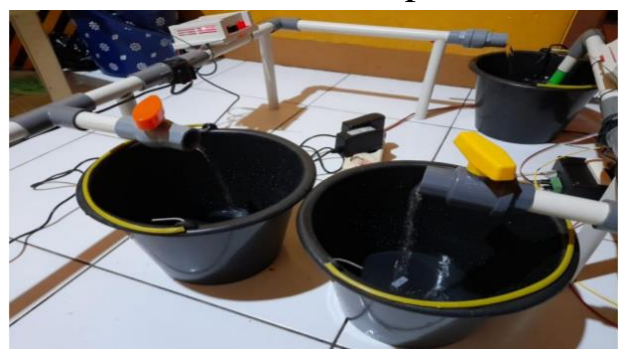

Gambar-21 Proses simulasi kebocoran pada kedua titik (titik A dan B)

2. Simulasi Kerusakan 
Simulasi kerusakan dilakukan dengan memutus hubungan pompa ke sumber listrik AC, kemudian dicek apakah sinyal pantul terdeteksi atau tidak. Gambar di bawah menunjukkan saat status tombol aktuator dan status sinyal pantul tidak sesuai, sehingga alarm kerusakan pompa menjadi aktif.

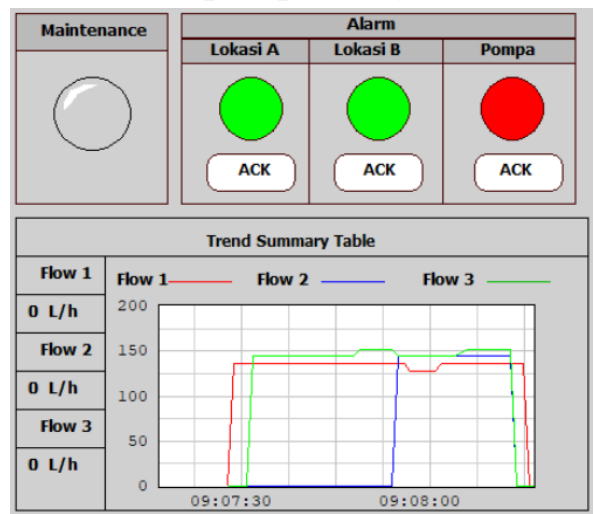

\section{Kesimpulan}

Gambar-22 Tampilan HMI saat pompa dalam keadaan rusak

Berdasarkan hasil perancangan dan pengujian pada sistem, diperoleh bahwa sistem yang dibuat sudah dapat melokalisir letak kebocoran pipa distribusi air pada dua lokasi, dengan menggunakan 3 titik pengukuran. Komunikasi terminal RTU pada setiap titik menggunakan jaringan RS485. Bagian HMI memiliki 3 level alarm, yaitu Normal, Warning, dan Danger yang masing-masing direpresentasikan dengan indikator warna hijau, kuning dan merah. Pendeteksian kebocoran berhasil dilakukan dengan menghitung nilai deviasi antara dua titik pengukuran. Pada penelitian ini didapat untuk kondisi Warning, deviasi $>7 \%$ dan $<=10 \%$, sedangkan untuk kondisi Danger, deviasi $>10 \%$. 
Tubagus Sundana, Farchan Aditya Johari dan Fathan Al Ariiq

\section{Bibliografi}

Briantama, uyun, akbar, ahmad anugrah, \& aziz, mohamat n. U. R. Rohman. (2021). MODIF: Sistem Monitoring Pengukuran Debit dan Kecepatan Air Berbasis LORA \& ESP8266 Dalam Mendukung Estimasi Daya Kerja yang Dihasilkan Mikrohidro dan Wilayah Konservasi Air pada Embung Kladuan.

Hariyanto, Duwi, Pauzi, Gurum Ahmad, \& Supriyanto, Amir. (2017). Deteksi Letak Kebocoran Pipa Berdasarkan Analisis Debit Air Menggunakan Teknologi Sensor Flowmeter Berbasis TCP/IP. Jurnal Teori Dan Aplikasi Fisika, 5(1), 25-30. DOI: http://dx.doi.org/10.23960\%2Fjtaf.v5i1.1355

Herwindo, Wildan, \& Rahmandani, Dadan. (2018). Kajian Rancangan Irigasi Pipa Sistem Gravitasi. Jurnal Irigasi, $8(2), \quad 126-137$. DOI: http://dx.doi.org/10.31028/ji.v8.i2.126-137

Heston, Yudha Pracastio, \& Pasawati, Nur Alvira. (2016). Analisis Faktor Penyebab Kehilangan Air PDAM (PDAM Water Loss Factors Analysis). Pros. Temu Ilm. IPLBI, 2016, 1-6.

Kusumawardani, Deni. (2011). Valuasi ekonomi air bersih di Kota Surabaya. Jurnal Ekonomi Dan Bisnis Airlangga, 21(3). DOI 10.20473/jeba.V31I22021.74-82

Munson B., dan D. Young. (2004). Mekanika Fluida. Jakarta.

Pratama Putra, Juliansyah. (2014). Studi Kehilangan Air pada Jaringan Distribusi PDAM di Jalan Soekarno-Hatta Palembang dengan Metode DMA (District Meter Area). Politeknik Negeri Sriwijaya.

Sadeghioon, Ali M., Metje, Nicole, Chapman, David N., \& Anthony, Carl J. (2014). SmartPipes: smart wireless sensor networks for leak detection in water pipelines. Journal of Sensor and Actuator Networks, 3(1), 64-78. https://doi.org/10.3390/jsan3010064

Tetty, S. R., Maman, A. and Novian, A. S. (2015). Perancangan Prototipe Sistem Pemantau Kebocoran Pada Pipa Distribusi Air Menggunakan Protokol Zigbee/leee 802.15.4 Dan Platform M2m. e-Proceeding of Engineering.

WIJAYA, HANDI T. I. O., \& PULUNGAN, DWIKI M. PAMORA. (2017). Analisa kehilangan air pada jaringan pipa distribusi air bersih dengan metode district meter area di kawasan karangan rambang kapak tengah prabumulih. Politeknik negeri sriwijaya. 